\title{
Formación de profesores de física e implicaciones de la relación ciencia, tecnología, sociedad y ambiente: posibilidades, desafíos y limitaciones
}

Physics Teacher' s background and implication of the science, technology, society and Emvironment relations: possibilities, challenges and limitations

João Amadeus Pereira Alves ${ }^{1}$, Rejane Aurora Mion ${ }^{2}$, Washington Luiz Pacheco de Carvalho ${ }^{3}$

${ }^{1}$ UNESP/PGFC e UEPG-DEMET, ${ }^{2}$ UEPG/PPGE-DEMET, ${ }^{3}$ UNESP/PGFC e DFQ/FEIS

japalves@yahoo.combr,. ramion@uepg.br,. washcar@dfq.feis.unesp.br

\section{Resumo}

Este trabalho faz parte de uma pesquisa mais ampla de natureza estudo de caso, a qual teve seus dados empíricos provenientes de um programa de investigação-ação educacional, em um aurso de formação inicial de professores de Física de uma universidade pública, diante da implementação de uma nova proposta pedagógica e curricular nesse curso. Neste trabalho defendemos a adoção e indusão da problematização das implicações da relação ciência, tecnologia, sociedade e ambiente (CTSA), mostrando a sua importância para a incorporação da cultura científica e tecnológica, em uma visão crítica de Educação. Isto exige que a formação dos professores tenha a problematização de tais implicações como conteúdo na prática de ensino da Física. Neste sentido, os pressupostos teóricos estão alicerçados em referenciais afinados com a Teoria Crítica de Educação.

\section{Palavras chave}

Formação de professores de Física, implicações da relação CTSA, investigação-ação educacional de vertente emancipatória.

\section{Abstract}

This study is part of a broad research based on a case study, which had its empirical data obtained from an educational action-research program, along an undergraduate physics teacher course of a public university, and it has been biased by the implementation of a new pedagogical and curricular govemmental proposal. In this study we argue favorably to the adoption and insertion of problematization concerning the implication of STSE (science-technology-societyenvironment) relation by showing its relevance for the process of scientific and technology acculturation, by adopting a critical view of Education, what demands that new teachers' education has problematization of such implication as curricular content of physics teaching practice. In this sense, the theoretical assumptions are based on authors who have affinity with a critical theory of Education.

\section{Keywords}

Physics teacher education, implications of STSE relation, educational action-research.

\section{Introdução}

As Diretrizes Curriculares para a Formação de Professores vigentes no Brasil trouxeram para a maioria dos cursos de licenciatura, em especial em Física, um acrésaimo significativo de carga horária para a disciplina e as atividades de Estágio, alcançando 400 horas-aula, no mínimo. Com 
isso, mudanças significativas ocorreram nesses aursos e, elas têm gerado desdobramentos que não podem ser compreendidos como puramente positivos somente. Concomitante a essas mudanças curriculares a comunidade científica intensificou os alertas aos governantes das nações mundiais sobre as mudanças climáticas na Terra. Por sua vez, a mídia, muitas organizações nãogovemamentais e outros seguimentos da sociedade passaram também a chamar atenção para as alterações climáticas que têm sido evidenciadas sob diferentes formas, em diferentes lugares da Terra e, pelo que se já tem comprovado, de modo ascendente. Os alertas passaram a ter maior efeito a partir das constatações mais contundentes oriundas de pesquisas e pesquisadores do IPCC (Intergovernmental Panel on Climate Change), que integra cientistas e outros profissionais dos mais variados países, inclusive do Brasil. Nesse cenário o ser humano é o protagonista principal e a sociedade em geral começa a se sensibilizar com aspectos envolvendo as mudanças dimáticas no planeta (Latour, 1994).

> "O que fazer?" Perguntam muitos.- "Difíal resposta para esta pergunta!" Diriam alguns.- "Desenvolver e implementar mais reaursos tecnológicos e investir mais dinheiro na ciência" Diriam aqueles que entendem que a tecnologia seja sua guardiã e amiga.

$>$ "Mudar, mas não de planeta. Mudar as ações, os interesses, as relações, as interrelações etc.!" Diriam alguns críticos, para entender e modificar o curso da própria ação (Strauss, 1999).

Mas, o que pode haver em comum entre as mudanças curriculares sofridas pelos cursos de licenciatura em Física e as significativas mudanças dimáticas na Terra? Para responder a essa questão é preciso considerar que as mudanças curriculares sofridas pelos aursos de licenciatura incrementaram para uma significativa parcela dos aursos já existentes, uma considerável carga horária para o desenvolvimento da disciplina e das atividades de Estágio. Tomando como referência as disciplinas de Estágio Curricular Supervisionado em Ensino de Física, de uma universidade pública, em que dois dos autores deste trabalho são docentes dessas disciplinas, esse incremento de carga horária foi de 71,5\% pois a mesma passou de 238 para 408 horas-aula - distribuídas em dois anos e em disciplinas anuais (204 hora-aula em cada ano).

Na universidade pública em que focamos nossos interesses de pesquisa, apresentados neste trabalho, a proposta para essa disciplina tem como um de seus objetivos inserir a problematização das implicações da relação Ciência, Tecnologia, Sociedade e Ambiente (CTSA) frente às necessidades inerentes à concepção de Educação Cient́fica e Tecnológica que temos e com a qual atuamos. Esta proposta está inserida em um programa de investigação-ação educacional de vertente emancipatória, que é desenvolvido no seio do processo ensino-aprendizagem, levado a cabo no decorrer da disciplina citada compreendendo as 408 horas-aula. Ou seja, isso tem possibilitado inserir intencionalmente os licenciandos no processo ensino-aprendizagem analisado, em um processo de conscientização referente às problemáticas sócio-ambientais atuais do planeta.

Entendemos que, somente a observação realizada sistematicamente no Estágio Curricular Supervisionado dos futuros professores garante a priori que se tenha elementos informativos e elucidativos capazes de permitir a reflexão crítica e o replanejamento das ações (Strauss, 1999). É isto que justifica a importância da proposta que apresentamos, para a formação do professor e pesquisador em ensino de Física: fazer parte de um programa de investigação-ação educacional de vertente emancipatória.

Em síntese, o cenário da pesquisa em foco, sobre a qual buscamos tomar visível neste trabalho sustenta-se pelos seguintes parâmetros: 
As implicações decorrentes das Diretrizes Curriculares para a Formação de Professores (de Física), bem como dos Parâmetros Curriculares Nacionais - PCNEM (Brasil, 1999) e das Orientagões Educacionais Complementares aos PCN (Brasil, 2002).

- A necessidade da adoção e inclusão e inserir as implicações da relação CTSA, para a incorporação da cultura científica e tecnológica, em uma visão crítica de Educação. Isto exige que a formação do "professor e pesquisador em ensino de Física" tenha a problematização de tais implicações como conteúdo na prática de ensino da Física.

Diante desse cenário, buscamos responder sobre Qual a importância para a incorporação da cultura científica e tecnológica da problematização das implicações da relação CTSA numa visão crítica em educação?

\section{Implicações da relação CTSA, Formação de professores de Física e Teoria Crítica em Educação}

A problematização das implicações da relação CTSA inauguram um novo tempo, em que as discussões da abordagem CTS (Ciência, Tecnologia e Sociedade) não oferecem as ferramentas necessárias às novas necessidades emergentes ao debate mais amplo referente aos aspectos sócioambientais (Ainkenhead, 2000; Pedretti et al., 2002; Carvalho, 2005) e a relação da educação científica e os problemas atuais da humanidade relativos a danos ambientais com seus efeitos locais e globais (Richardson e Blades, 2002; Gil-Perez, 2003; Tesla et al., 2007).

Nas décadas de 1970 e 1980, educadores e pesquisadores renomados intemacionalmente como Glen Aikenhead, Joan Salomon, John Ziman e outros influenciaram as pesquisas em educação e as políticas públicas educacionais em Ciências de seus países, produzindo trabalhos substanciais sobre a abordagem CTS. Mas nessas produções não se traziam ou não se evidenciava a dimensão ambiental como um pressuposto importante, pois aspectos dessa natureza aparediam de modo bastante periférico nos diferentes contextos educacionais em ciências (literatura e academia).

Produções fundamentadas na reflexão sobre as próprias práticas como as de Blomfield (1997) e GREF (2002a;b;c) subsidiam orientações importantes para prática docente em Física. São obras que apresentam possibilidades para se contextualizar o processo ensino-aprendizagem da Física, viabilizando situações de diálogo, o que está em acordo com a educação dialógicoproblematizadora (Freire, 1983) que defendemos. Tomados com esse interesse estas obras têm subsidiado nosso interesse pela transformação de objetos técnicos em equipamentos geradores (Mion, 2001; 2002).

Entretanto, Blomfield (1997) e GREF (2002a;b;c) orientam pouco para discussões sobre as implicações sócio-ambientais, pois se o primeiro apresenta o interesse mais direcionado à compreensão dos objetos técnicos sem contextualizar aspectos sócio-ambientais, o segundo apresenta uma linha de pensamento de um período que pouco considerava interesses mais detidos às questões sócio-ambientais. É fundamentalmente importante que deixemos daro que essas observações não inviabilizam a utilização das mesmas, principalmente porque no nosso entendimento Blomfield (1997) e GREF (2002a;b;c) são compatíveis à Teoria Crítica de Educação, porém, isso exige uma capacidade criativa no planejamento de planos de curso e de aulas, de atividades relativas a esses planejamentos, bem como da avaliação dessas ações de modo retrospectivo e perspectivo (Angulo, 1990), no curso da ação (Strauss, 1999), de modo que possamos fazer a inserção da problematização das implicações da relação CTSA. São atividades que permitem entrar em cena temas contemporâneos, como mudanças dimáticas associadas à compreensão da Física Térmica, que levem em conta aspectos como aquecimento global e efeito estufa; derretimento das calotas polares; a abertura na camada de ozônio; poluição atmosférica. 
Vê-se nesse viés aspectos relativos à natureza da ciência e da tecnologia sobre questões sócioambientais.

À luz de outros fundamentos teóricos percebemos que a inserção da problematização das implicações da relação CTSA na prática educativa em Física deva ocorrer sob uma visão da Teoria Crítica em Educação. Nessa visão, o professor não atua como agente depositário de respostas prontas (Freire, 1983), mas o faz de modo que a Ciência, a Tecnologia, a Sociedade e o Ambiente sejam compreendidos como mutuamente influentes entre si - elementos produtores de relações sociais e técnicas em tempo integral (Latour, 2000).

Essa problematização não ocorre por si só; não é encontrada em manuais. Ela diz respeito a um fenômeno social na prática educacional, quando os alunos podem elaborar e re-elaborar questionamentos (McLaren, 1997); produzir significações autônomas e coletivas; podem se apossar de representações de outros, interpretá-las e modificá-las. Assim, não se pode falar de prática educativa problematizadora sem pensar e trabalhar com a formação do professor. Há, portanto, a necessidade de a formação do professor acontecer à luz da problematização das implicações da relação CTSA, a partir de conhecimentos teóricos e práticos, em que a elaboração de suas atividades se faça no interior de uma comunidade cuítica. Isto também não pode ser buscado em manuais, mas deve ser realizado nos cursos de formação de professores inicial e continuada, onde se possam constituir as comunidades críticas de investigadores.

A opção que temos pela Teoria Crítica para dar sustentação à concepção de pesquisa em ensino de Física encontra-se respaldada por McLaren (1997), em que:

A natureza dialética da teoria crítica permite ao pesquisador em educação ver a escola não simplesmente como uma arena de doutrinação ou socialização ou um local de instrução, mas também como um terreno cultural que confere poder ao estudante e promove a autotransformação (McLaren, 1997, p. 200).

Nesse sentido, a problematização de tais implicações encontra na Teoria Crítica os subsídios para a formação do professor e pesquisador - crítico, que consegue ver sob múltiplos lados o mesmo problema (McLaren, 1997), seja ele ligado a interesses de dasse, raça e gênero, conforme destaca 0 autor, seja ele ligado a interesses científicos, tecnológicos, sociais e ambientais.

Portanto, os preceitos da teoria crítica subsidiam algumas ferramentas que tornam o sujeito capaz de epistemologicamente mudar a sua condição (Freire, 1983); que permite ao professor constituir a sua identidade profissional (Strauss, 2000) na medida em que reflete sobre sua própria ação (Freire, 1983) e a transforma sob o viés do trabalho colaborativo na reconstrução racional da história da própria prática (Mion, 2002).

Na concepção de Pucd (1995), a Teoria Crítica fez com que edodissem contribuições muito significativas de análise entre o poder e a cultura na sociedade contemporânea. Por outro lado, a teoria crítica em educação prescinde de oferecer tais contribuições, de análise, já na formação inicial dos professores, o que justifica os nossos interesses de pesquisa.

Mas qual modalidade de Educação é essa? Para responder a essa questão vejamos o que diz Freire (1983, p. 97): "Para o ingênuo, o importante é a acomodação a este hoje já normalizado. Para o crítico, a transformação permanente da realidade, para a permanente humanização dos homens". Este autor, ao tratar da relação homem-mundo, afirma que: "Nosso papel não é falar ao povo sobre a nossa visão do mundo, ou tentar impô-la a ele, mas dialogar com ele sobre a sua e a nossa" (Freire, 1983, p. 97). 
Nesse contexto, nossa proposta de formação de professores de Física, embasada pela Teoria Crítica em Educação, encontra limitações sob diferentes lados e de diferentes instâncias institucionais atreladas à formação do professor. Com isso, temos que replanejar nossas ações, reavaliando e a auto-avaliando com muito mais cuidado o processo e as nossas próprias ações.

\section{A metodologia da Pesquisa}

Trata-se de uma pesquisa do tipo estudo de caso. De acordo com Lüdke e André (1986) e Bogdan e Biklen (2002), são características indissociáveis do estudo de caso: visa à descoberta; enfatiza a interpretação em contexto; retrata a realidade de modo completo e aprofundado; dispõe de variadas e ricas fontes de informações; permite generalizações naturalísticas (do conhecimento experiencial do sujeito); procura representar diferentes e por vezes conflitantes pontos de vista de uma situação social.

$\mathrm{Na}$ pesquisa em foco, o estudo de caso ocorreu sobre um programa de investigação-ação educacional emancipatória, diante de uma proposta de formação do professor e pesquisador em ensino de Física, que busca atender às exigências das Diretrizes Curriculares Nacionais para os cursos de licenciatura. Esse programa representa, portanto, o resultado da experiência iniciada em 1997 na formação de professores de Física, em uma instituição de ensino superior público. Os fundamentos teóricos e práticos da proposta são oriundos da Teoria Crítica em Educação.

O desenvolvimento, análise, reflexão e novos direcionamentos da nova proposta de estágio curricular supervisionado fora acompanhada em todo o seu decorrer - entre março de 2006 (início) e dezembro de 2007 (final). Os dados empíricos foram coletados por meio de observações diretas (registros manuscritos em diários de campo), gravações eletrônicas, reflexões e análise documental, entre março de 2006 e dezembro de 2007 junto ao referido programa.

No que diz respeito aos momentos próprios da investigação-ação educacional relativa ao referido programa de formação de professores, na proposta de estágio desenvolvemos a disciplina de Estágio Curricular Supervisionado em Ensino de Física tendo a rigorosidade metódica sustentada, dentre outras coisas, pelos momentos de planejamento, ação, observação e reflexão (Angulo, 1990).

Diante das observações realizadas, seguindo um roteiro (Mion, 2002), trazemos na seqüencia alguns resultados e discussões da proposta de formação do professor e pesquisador sob uma visão alicerçada em Strauss (1999) e na Teoria Crítica em Educação, com fundamentos em Giroux (1986 e 1997), Mion e Angotti (2001); MdLaren (1997) e Strauss (1999).

\section{Resultados e considerações}

Buscando a inserção de tal problematização nas aulas de formação inicial de professores, nas disciplinas de Estágio Curricular Supervisionado em Ensino de Física, a observação (sistematizada em registros em diários de campo) de uma das aulas no curso de formação de professores revela a intencionalidade do professor. Na discussão gerada acerca de vídeos produzidos pela BBC de Londres, evidencia-se a necessidade de formação do professor estar alicerçada pela inserção de tal problematização, pois: "Foram feitas referências sobre os pontos apresentados nesse vídeo não serem discutidos nas disciplinas de conteúdo espećfico da Física e da Química" (Diário de Campo, 15 março 2007).

0 manuseio reflexivo de objetos técnicos (Mion e Angotti, 2001) em plena função social, e a problematização de conceitos e práticas com a estruturação de redes conceituais foi um meio que 
subsidiou o planejamento e a "visualisação" das implicações da relação CTSA. Neste sentido se pode compreender uma dificuldade anterior ao manuseio reflexivo - trata-se de como se chegar a definição de um objeto técnico principal para subsidiar um plano de curso ou de unidade.

A avaliação da implementação da proposta e da disciplina ocorreu no curso das suas ações (Strauss, 1999), tendo como focos principais: durante todo o ano de 2006 - o período de fundamentação teórica, passando pela elaboração dos projetos individuais de ação e/ou investigação e culminando com a apresentação coletiva de tais projetos e; durante 0 ano de 2007 o período de desenvolvimento desses projetos, contemplado nos momentos da investigação-ação educacional. Além disso, se pôde constatar que os conhecimentos próprios da subárea de Física e da didática da Física são insuficientes para sustentar tais discussões, o que se mostra como um importante desdobramento decorrente da interpretação e implementação das novas Diretrizes Curriculares Nacionais.

A intenção de problematizar as implicações da relação CTSA no aurso de formação do professor se configura viável a partir dos objetivos de uma proposta e de um programa. Na leitura que Peter McLaren faz de obras de Henry Giroux, os objetivos podem ocorrer sobre duas perspectivas: macro e microobjeticos. Os macroobjetivos destinam-se a "permitir que os estudantes façam conexões entre os métodos, conteúdo e estrutura de um curso e seu significado dentro da ampla realidade social" (Mclaren, 1997, p, 201). Quanto aos microobjetivos, Mclaren (1997, p. 201) diz que eles "representam o conteúdo do curso e são caracterizados pela sua estreiteza de propósito e seu curso de investigação ligado ao conteúdo".

A utilização de vídeos sobre aquecimento global correspondeu a um microobjetivo para a investigação temática, mas também correspondeu a um macroobjetivo para a elaboração de redes conceituais. Assim, em Freire (1983) teríamos a compreensão de que codíficamos quando utilizamos os vídeos inicialmente, descodificamos na elaboração das redes conceitos, enquanto que a recodificação deveria ficar "a cargo" do entendimento da Física pelos alunos do ensino médio nas relação ente Ciência (Física), Tecnologia, Sociedade e Ambiente.

É preciso levar em conta que esse comprometimento é frágil entre os envolvidos na proposta de estágio. Isso decorre da tradição educacional vivida pelos mesmos, muito afinada com práticas educacionais bancárias (Freire, 1983).

\section{Conclusão}

A partir desse estudo de caso, constatamos que a problematização das implicaçães da relação CTSA ocorre se a sua inserção for tida como uma intencionalidade na formação do professor de Física, portanto, tendo como pressuposto o fato de que ela deva ser tratada como conteúdo próprio dos cursos de formação e, obviamente, portanto, amparada por uma abordagem fundamentada na Teoria Crítica de Educação.

Diante disso, a inserção dessa problematização precisa, educacionalmente, contribuir na superação da concepção ingênua de ensino de Física, promovendo assim a ruptura com uma concepção bancária de Educação (Freire, 1983), o que demanda de ser uma tarefa do professor formador de professores a mudança de concepção de formar professores (Mion, 2000) - isto é, investir na formação do professor e pesquisador.

Portanto, a pesquisa precisa ser assumida como prinćpio de Educação, princípio formativo e de trabalho. Assim, precisa também que no processo ensino aprendizagem na formação inicial do professor de Física, a prática da pesquisa seja incluída no curso de formação desses professores. 


\section{Referências}

ANGULO, J. F. (1990). Investigación-acción y curriculum: una nueva perspectiva en la investigación educativa. Investigación en la Escuela. 11, 39-49.

BLOOMFIELD, L. A. (1997). How Things Work The Physics of Everyday Life. USA: J.Wiley.

BOGDAN, R. e BIKLEN, S. (1994). Investigação Qualitativa em Educação: uma introdução à teoria e aos métodos. Porto: Porto Editora.

BRASIL (1999). Ministério da Educação. Parâmetros Cumiaulares Nacionais para o Ensino Médio. Brasília: MEC.

BRASIL (2002). Ministério da Educação. Orientacões Educacionais Complementares aos Parâmetros Curriculares Nacionais. Brasília: MEC.

CARVALHO, W. L P. (2005). Cultura Científica e Cultura Humanística: espaços, necessidades e expressões. Tese (Pós-Doutorado) - Faculdade de Engenharia, Universidade Estadual Paulista, Ilha Solteira.

FREIRE, P. (1983). Pedagogia do Oprimido. 15. ed. Rio de Janeiro: Paz e Terra.

GIL-PEREZ, D. et al. (2002). A Educação Científica e a Situação do Mundo: um programa de atividades dirigido a professores. Ciência \& Educação. 9 (1), 123-146.

GIROUX, H. (1986). Teoria Crítica e Resistência em Educação: para além das teorias de reprodução. Tradução de Ângela Maria B. Baggio. Petrópolis: Vozes.

. (1997). Os Professores como Intelectuais: rumo a uma pedagogia crítica da aprendizagem. Tradução de Daniel Bueno. Porto Alegre: Artmed.

GREF. (2002a). Grupo de Reelaboração do Ensino da Física. Física 1: Mecânica. São Paulo: EDUSP.

. (2002b). Física 2: Física Térmica, Ótica. São Paulo: EDUSP.

. (2002c). Física 3: Eletromagnetismo. São Paulo: EDUSP.

LATOUR, B. (1994). Jamais Fomos Modemos. Tradução de Carlos Irineu da Costa. Rio de Janeiro: Ed. 34.

. (2000). Cếncia em Ação: como seguir cientistas e engenheiros sociedade afora.

Tradução de Ivone C. Benedetti. São Paulo: Ed. Unesp.

LÜDKE, M. e ANDRÉ, M. E. D. (1986) Afonso. Pesquisa em Educação: abordagens qualitativas. São Paulo: EPU.

McLAREN, P. (1997). A vida nas escolas: uma introdução à pedagogia crítica nos funda mentos da educação. Tradução de Lucia Pellanda Zimmer et al.. $2^{a}$ edição. Porto Alegre: Artmed.

MION, R. A. et al. (2000). Mudando o trabalho educativo de formar professores de Física. Perspectiva. 18 (33), 93-114.

MION, R. A. e ANGOTTI, J. A. (2001). Equipamentos Geradores e a Formação de Professores de Física. In: ANGOTTI, J.A. e REZENDE JUNIOR, M.F. (Orgs.). Prática de Ensino de Física. (pp. 91116). Florianópolis, Laboratório de Ensino de Física à Distância. - (2002). Investigação-ação e a formação de professores em Física: o papel da intenção na produção do conhecimento aŕtico. Tese (Doutorado em Educação) - Centro de Educação, Universidade Federal de Santa Catarina, Florianópolis.

PEDRETTI, E. et al. (2002). Enhancing STSE Práxis Through Action Research. NARST 2002 Proposal. Disponível em: <http://uww.uontario.ca/narst>. Acesso em: 28 janeiro 2002.

RICHARDSON, G. e BLADES, D. (2002). Social Studies and Science Education: developing world citizenship through interdisciplinary partnerships. Alberta: LCD. 
STRAUSS, A. (1999) Espelhos e Máscaras. Tradução de Geraldo Gerson de Souza. São Paulo: EDUSP.

TESLA, I et al. (2007). Developing Teachers' Professional Competencies: some results concerming an activity about greenhouse effect V-ESERA, Barcelona, 2005. Disponível em: <http://www.esera.org/vesera.pdf>. Acesso em: 11 abril 2007. 